\title{
AS DERIVAÇÕES ENCICLOPÉDICAS NO HERMETISMO MEDIEVAL E SEUS VESTÍGIOS NA CIÊNCIA DO SEISCENTOS: UM ESTUDO SOBRE OS TRÂNSITOS E CORRELAÇÕES ENTRE DOIS NICHOS DOCUMENTAIS ${ }^{1}$
}

Ana Maria Alfonso-Goldfarb*

\section{Resumo}

Através de análises contínuas em nichos documentais distintos foi possível verificar que, independente da época, a organização dos conhecimentos sempre estava diretamente envolvida com a organização textual. Essa seria, portanto, um bom indicador da rota tomada por antigas fontes, mesmo em períodos, como foram os séculos XVI e XVII, marcados por uma confusa relação entre a continuidade e a descontinuidade no pensamento. Tornase possível, assim, mapear os paralelos e permanências entre momentos tão distintos como aqueles onde se gerou a hermética medieval e o que deu nascimento à ciência moderna, sem perder a especificidade de cada um deles. A crítica textual (derivada da filologia) e a historiografia contemporânea em história da ciência serão usadas, respectivamente, nas análises de texto e contexto de cada um desses dois momentos.

\section{ALGUMAS CONSIDERAÇÕES SOBRE O PADRÃO TEXTUAL DO ANTIGO ENCICLOPEDISMO}

Ao que parece, um dos vetores a transportar consigo antigas concepções de mundo e matéria, para além do século XV, foi a polimatia renascentista.

* Master Of Arts - Filosofia e História da Ciência pela Mcgill University e doutora em História Social pela Universidade de São Paulo. Professora assistente doutora da Pontifícia Universidade Católica de São Paulo. (aagold@dialdata.com.br)

1 Esta pesquisa teve apoio do CNPq e da FAPESP. 
Enquanto provável derivação da poligrafia clássica, a polimatia renascentista ainda guarda a fórmula organizativa do enciclopedismo antigo. Estudiosos definem esse enciclopedismo original como sendo a obra de um só autor, ou de autores trabalhando a quatro mãos, recolhendo fragmentos, às vezes aos milhares, das mais variadas fontes. Organizadas por temas, essas velhas formulações enciclopédicas buscavam abarcar, de uma só vez, o contorno do saber universal. Fosse incluindo longos arrazoados sobre a natureza - dos quais até hoje, são uma das maiores fontes para a história da ciência -; fosse fixando, em alguns casos pela primeira vez, antigas lendas orais; fosse ainda tornando conhecidos os relatos cosmogônicos ou históricos de documentos templários ou oficiais; essas enciclopédias se constituíram de várias formas em períodos distintos. As mais conhecidas foram as de autores como Estrabo e Plínio. Mas polígrafos cristãos, como Santo Eusébio e Isidoro de Sevilha, fizeram obras que também podem ser consideradas de cunho enciclopédico. Da mesma forma, os antigos livros de segredo aparecem articulados como verdadeiras enciclopédias das artes e ofícios seja em tratados de hermética popular, livros de venenos ou naqueles sobre feitos maravilhosos, compilados desde a Antigüidade tardia ${ }^{2}$.

De fato, muitas das obras que geraram a Ciência Moderna caracterizam-se como estando num limiar. Por um lado captavam, ainda, muito dessa lógica totalizante dos saberes entrelaçados por temas, dominados por um único indivíduo, através de centenas de vozes trazidas do passado. Mas, por outro lado, iniciavam já, um contato com a nova cosmologia e as novas idéias que, inexoravelmente com o tempo, iriam substituir o projeto enciclopédico antigo do saber. Esse autores, porém, vivem apenas o começo do fim desse projeto e, portanto, estão ainda muito

2 Sobre as origens e transformações da antiga fórmula textual enciclopédica vide, por exemplo. W. Anderson, "Encyclopedic Topologies", Modern Language Notes, vol 101, 1986, p. 912-29; A. Grafton, "The World of Polyhistors: Humanism and Encyclopedism", Central European History, vol 18, 1985, p. 31-47; e particularmente a série de artigos, que teriam iniciado o debate sobre o tema, publicados no Jounal of World History, vol. 9, $\mathrm{n}^{0} 3$, 1966. Para o mapeamento dessas transformações até o nascimento da ciência moderna vide meu artigo "O antigo enciclopedismo e a ciência moderna”, Anais - VII Seminário Nacional de História da Ciência e da Tecnologia, J.L. Goldfarb \& M. Ferraz (orgs.). Imp. Oficial/ Edusp/ Edunesp, São Paulo: 2000, p. 55-60. 
distantes da frutificação do novo projeto que, eles próprios, ajudaram a criar.

A fim de melhor entender as transformações e especificidades em diferentes períodos da forma de pensamento articulada pelo antigo enciclopedismo, usou-se dois nichos documentais que temos estudado a tempo. Um primeiro, centrado no século XVII, particularmente na Ciência inglesa tendo como estudo de caso a obra J. Wilkins que influenciou toda uma geração de pensadores britânicos. Esse primeiro nicho beneficiouse do trabalho com as fontes desenvolvido num segundo que, centrado na Ciência Árabe dos séculos IX a XI e particularmente na hermética, foi dedicado ao estudo de tratados do período como o Livro do Tesouro de Alexandre.

Anteriormente, esses dois nichos de documentos - fosse o relacionado à obra de hermética árabe, fosse o relacionado à obra de J. Wilkins - eram analisados a partir de seus respectivos conteúdos, contextos e fontes ${ }^{3}$. Todavia, como bem lembram os estudiosos da crítica textual $^{4}$, nenhuma análise conteudística alcança a agudeza daquela dedicada a verificar a composição do texto. E uma não se completa sem a outra. As mudanças textuais representam mudanças também na visão do mundo e da natureza. Tal norma, - seguida à risca pela historiografia contemporânea em História da Ciência - serviu a pesquisa deste último período que, mantendo os mesmos focos de investigação, passou a analisar como se organizam e articulam os saberes nesses dois grupos de textos.

Um primeiro estudo indicava que ambos estariam obedecendo a antiga formulação enciclopédica. Mas, em obras como o Livro do Tesouro de Alexandre, essa composição enciclopédica ainda simbolizava a própria forma antiga de articular o conhecimento. Enquanto em obras como a

3 Vide, no primeiro caso, meu A magia das máquinas: J. Wilkins e a origem da mecânica moderna. São Paulo, Experimento: 1994; enquanto que no segundo caso, vide meu Livro do Tesouro de Alexandre: um estudo de hermética árabe na oficina da História da Ciência; trad. original árabe S. Jubran \& A.M. Alfonso-Goldfarb, Petrópolis, Vozes: 1999.

4 Vide, por exemplo, S. Spina, Introdução à Edótica - Crítica Textual. 2. ${ }^{\text {a }}$ ed. São Paulo, Ars Poética/ Edusp, 1994. 
de Wilkins, essa composição seria vestigial, pois já se prenunciam novas formas de articular, e até mesmo desarticular, o conhecimento.

O aprofundamento e comparação dessas duas análises, portanto, auxiliou a melhor compreensão do complexo processo de continuidades e descontinuidades que transformou lentamente o discurso polimático naquele do especialista moderno.

\section{A FORMULAÇÃO ENCICLOPÉDICA SINGULAR EM TRATADOS DE HERMÉTICA ÁRABE COMO O LIVRO DO TESOURO DE ALEXANDRE}

Estudos preliminares indicaram que os tratados de hermética, sobretudo da hermética árabe, como o Livro do Tesouro de Alexandre, seriam uma compilação feita a partir de muitas outras compilações, daí adquirindo sua forma labiríntica. Uma trama elaborada a partir de verdadeiras constelações discursivas - distribuídas ora de maneira mais densa ora de maneira rarefeita e freqüentemente combinando-se entre si - sobre as quais já falavam no séc. X os Ikhwan al-Safa (irmãos de pureza), em sua enciclopédia dedicada a hermética. Segundo eles, quatro entre essas possíveis combinações dariam as leis e demonstrações de quatro grandes ciências destinadas aos iniciados e perigosas quando entregues a mãos sem preparo: a medicina, a química, a astrologia e a ciência dos talismãs. A autoria dessas obras é atribuída pelos Ikhwan aos (pseudo) sabeans de Harran. Um povo que seria detentor de antigos conhecimentos mesopotâmicos e teria aprendido a complexa arte combinatória dos discursos. Estes, naturalmente, não eram discursos comuns, mas discursos a respeito de "segredos".

Sobre a articulação dessa trama, também falam os Ikhwan, distinguindo as quatro espécies de "livros" que a compõem:

“(1) livros de matemática, de ciências da natureza, escritos a partir dos ensinamentos de sábios e filósofos / (2) livros revelados transmitidos pelos profetas (...)/(3) livros sobre a física, ou seja, sobre a forma dos existentes, tanto terrestres como supralunares e, no primeiro caso, tanto os produtos da 
indústria humana quanto os seres naturais, todas essas coisas constituintes dos signos de realidade sutis e de fins secretos (...) / (4) livros sagrados que podem ser tocados apenas pelos puros: os anjos e as substâncias das almas (...)". 5

Esse enovelado de saberes - que hoje parecem díspares - lembra, por contigüidade, as poligrafias clássicas. Tal parece ser a organização mantida pela hermética árabe, provável herança da hermética popular/técnica escrita na Antiguiidade. Obras como a de Jabir, dos Ikhwan al-Safa, ou aquelas de possível estamento harranita como o Livro do Tesouro de Alexandre, manteriam, portanto, a conformação de uma antiga enciclopédia. Somente que, segundo visto acima, essa não seria uma enciclopédia dedicada ao saber comum, mas às artes, às ciências e aos fundamentos secretos. Enfim, uma enciclopédia tentando abarcar o todo dos saberes reservados a poucos. ${ }^{6}$

Hermes Trismegisto foi visto, através dos séculos, como um dos primeiros mestres e o maior dos polímatas que a humanidade conheceu ${ }^{7}$. É natural, portanto, que nas obras atribuídas a essa figura lendária compareçam, e mantenham íntima relação, os saberes mais exclusivos e cobiçados desde a Antigüidade. Não seria, aliás, prerrogativa da hermética enxergar o conhecimento como um único tronco no qual convivem e do qual se espraiam vários ramos. Essa fórmula entrelaçada dos vários conhecimentos parece ter se mantido nas práticas de diversas ciências, como a química e a medicina, ainda em pleno século XIX, enquanto os debates teóricos já

5 Cf. citação no estudo introdutório de G. de Callataÿ em sua tradução à Epístola XXXVI dos Ikhwan em sua org/ trad. Les revollution et les cycles: Épitres XXXVI, Beirute, Brylant, 1996. p. 11-12.

6 Sobre o epistolário ou enciclopédia dos Ikhwan, vide novamente o estudo introdutório de G. de Callataÿ, op. cit.; como também a introdução de A. Bausani, L’Enciclopedia dei Fratelli della Puritá, Nápolis, Istituto Universitário Orientale, 1978. P. Kraus “Julius Ruska”. Osiris. V (Bélgica, 1938), pp. 5-40., p. 316, indica a possibilidade dessa tendência na obra jabiriana; e a p. 275 et seq. traça paralelo entre a obra enciclopédica de Jacob de Edessa e o tratado hermético Sirr al-khaliqa atribuído a Balinas; M. Manzalaoui, "The Pseudo-Aristotelian K. Sirr al-Asrar”, Oriens, Vol. 23-4, 1974, p. 193, se refere a essa conformação como algo talvez introduzido no texto do Sirr al-Asrar a partir de acréscimos de revisores.

7 Vide meu artigo "Questões sobre a hermética: um reflexão histórica sobre algumas raízes pouco conhecidas da ciência moderna”, em Cultura Vozes, ano 88, vol. 88, n. 4, julho/agosto de 1994. 
tendiam à segregação e à especialização das ciências, destacando, assim, a visão analógica, qualitativa e totalizante do cosmo que, por milênios, havia justamente promovido a integração dos saberes ${ }^{8}$.

Ao que parece, obras herméticas como o Livro do Tesouro de Alexandre não estariam modificando o quadro tradicional do saber, mas apenas imprimiram a este uma combinação que, a um só tempo, valorizasse e resguardasse o que acreditavam existir ali de mais precioso e exclusivo. Esse conjunto de textos constitui um exemplo basilar da chamada literatura de segredo. Uma literatura que ainda influenciou enormemente os autores dos séculos XVI e XVII ${ }^{9}$. O estudo de sua complexa formulação, portanto, ajudou a compreender não só um ramo importante do antigo enciclopedismo, como também as suas manifestações futuras nos textos da nova ciência.

Todavia, no que tange a especificidade da articulação hermética, a pesquisa revelou pontos bastante interessantes. Naturalmente, conforme adverte G. Callatay, estudioso da obra dos Ikhwân acima mencionada, estes não estariam se referindo a livros comuns, encontrados nas prateleiras de qualquer biblioteca, mas àqueles retirados de grandes livros secretos sobre mundo e matéria. Ao guardar as fontes transmitidas pelas tábuas herméticas e recolher séculos e séculos de tradição oral, ${ }^{10}$ esses "livros" exigiam uma leitura iniciática. Ademais, visto que nem tudo o que tinham a

8 Vide a esse respeito o meu artigo "Estudos químicos -médicos: as águas minerais e seu histórico", Química Nova, Vol. XIX: 2, 1996; a permanência da velha visão nos trabalhos práticos do século XIX, enquanto as novas teorias colocavam já modelos bem diferentes, pode ser vista, por exemplo, no dicionário químico do século XIX, escrito por M. H. Klaproth e F. Wolff.

9 W. Eamon, Science and the Secrets of Nature: Books of Secrets in Medieval and Early Modern Culture $3^{\circ}$ ed., Princeton/N. Jersey, Princeton Univ. Press, 1996, parte I; Charles B. Schmitt, Aristotle and Renaissance, Cambridge/ Londres, Harvard Uni. Press, 1983. introd. e cap. I; Brian O. Copenhaver (org./ trad./ estudo) Hermética. Cambridge Uni. Press, 1992; Intro., Cap. I. Vide também meu artigo "Ciência, Magia e a Origem do Universo", in Ciência \& Ambiente, n. 14, jan/jun de 1997.

${ }^{10}$ A tradição oral foi um dos elementos constitutivos das culturas tradicionais; em algumas destas chegou a ser considerada tão ou mais importante do que a escrita; e mesmo ao ganhar o suporte da escritura, continuou a ser vista com deferência especial; vide, por exemplo, as explicações de R. C. Musaph-Andriesse, From Torah to Kabbalah, N. York, Oxford Univ. Press, 1982; particularmente sobre a importância da tradição oral para as culturas mezzo-orientais que dominaram a escrita, notadamente a judaica e a árabe. 
dizer estava expresso em seus textos, convencionando-se chamá-los "livros de segredo": textos feitos para poucos. ${ }^{11}$

Serão novamente os Ikhwân quem menciona o complexo trabalho iniciático dos hermetistas para recuperar - a partir dos "livros de segredo" - os arquétipos do saber que um dia Hermes ensinara. Pois, nos textos circunscritos à corporações e castas fechadas haveria a possibilidade de combinar palavras e letras de modo a formar múltiplos discursos constelares. Mas apenas quatro desses possíveis discursos guardariam as "leis e demonstrações" mais secretas das grandes ciências sagradas:

"a medicina: graças a qual [...] se habita o templo [do corpo] de maneira proveitosa/a chymia: graças a qual são expulsas a pobreza e a miséria/a astrologia: graças a qual se sabe $o$ devir/a ciência dos talismãs: graças a qual os seres adquirem a natureza dos reis e os reis, a natureza dos anjos". ${ }^{12}$

Somente os iniciados - inclusive aqueles pertencentes às exclusivas corporações de ofício - teriam o privilégio de encontrar todos esses discursos, que haviam sido ocultos nos textos para evitar seu uso por mãos ineptas ou mal intencionadas.

Os tratados de hermética, portanto, não seriam a simples junção dos "livros de segredo". Mais ainda, as constelações de discursos secretos, retiradas desses "livros" através da combinação de seu texto, eram novamente recombinados - só que de forma muito especial - constituindo, assim, os tratados herméticos. Aliás, o termo constelação define bem a forma adquirida pelos discursos secretos nas obras herméticas: densos naqueles tópicos e capítulos em que estava concentrado seu tema, estes vinham dispersos no resto da obra. Não obstante, sempre iam formando combinações surpreendentes ao longo do texto, que percorrem como um todo. Muitas vezes, as respostas a questões levantadas num tópico

11 Vide W. Eamon, op. cit., em que se oferece como matrizes dos chamados "livros de segredo" desde obras sobre artes e ofícios até obras filosóficas e religiosas; conforme veremos mais adiante, estas eram com freqüência obras dedicadas e usadas por círculos restritos.

${ }^{12}$ I. Marquet, "Sabeéns et Ihwan al-Safa”, Studia Islamica, Vol. 24, 1966, p. 49; esse texto em particular é uma tradução da própria enciclopédia dos Ikhwân. 
encontram-se em outro tópico ou capítulo. Outras tantas, faz-se necessário pinçar fragmentos dispersos por toda a obra para dar completude a idéias, receitas, histórias e conceitos apenas insinuados - ou incompreensíveis num dos tópicos. ${ }^{13}$

Justifica-se, desta forma, a eterna dificuldade para se lidar com as obras da hermética. Seu texto manhoso, às vezes parecendo não fazer sentido ou estar incompleto, revela-se quando analisado cuidadosamente como um todo. São obras que, apesar de remeter a outras infinitas obras, fecham-se sobre si mesmas, recuperando a forma arquétipa - simbólica e completa - que as lendas atribuíram ao conteúdo gravado por Hermes em tábuas pétreas.

Enfim, no pequeno espaço limitado pelos fólios de uma obra hermética coube - ou, ao menos, representou-se - por inteiro, o corpus dos saberes mais valiosos e secretos. Trata-se de um corpus fragmentado e refletido de maneiras variadas ao longo da obra, de modo a tornar, suas partes difíceis de entender ou até incompletas, quando desvinculadas de seu todo.

Assim, à medida que os tratados herméticos, com o passar do tempo, foram se desmembrando em tratados iatromágicos, iatromatemáticos/ astrológicos , e sobretudo alquímicos, a ruptura de seu vínculo com aquele contexto original da hermética transformou vários deles em obras truncadas e até mesmo sem pé nem cabeça. Prometendo um saber completo que, na verdade, não podiam oferecer, muitas dessas obras se revestem de um simbolismo indecifrável, a fim de ocultar um conteúdo frágil. Algumas mimetizaram o título de antigas obras herméticas, mas, naturalmente, não lograram mimetizar seu conteúdo. Outras, ainda, pinçavam partes, fórmulas e receitas da hermética que, arrancadas de seu nicho original, exibiam nostálgicos fragmentos deste, e mostravam-se claramente truncadas e fora de contexto.

O empobrecimento e as estranhezas desses novos textos foram notados por vários estudiosos modernos. Não obstante, continuaram a fazer referências a esses textos - em especial aos alquímicos - sem diferenciá-

${ }^{13}$ Essa técnica de composição do texto hermético era chamada de "dispersão do conhecimento" (tabdid al- 'ilm); o domínio dessa técnica era considerado um bom exercício de iniciação; cf. P. Kraus, Contribution à L'Historie des Idées Scientifiques dans L'Islam, Paris, Les Belles Lettres, 1986. 
los dos textos herméticos. Além de confundir a parte com o todo, esses estudiosos parecem não ter apreendido o quanto era mais complexo 0 "todo" hermético do que essas esquálidas "partes". ${ }^{14}$

De qualquer forma, ainda está em pleno andamento um debate sobre a origem e a definição do que passou a ser conhecido como hermética. ${ }^{15}$ E, se a Chymia que percorre o texto hermético não pode ser reduzida àquela existente em textos alquímicos e/ou químico-técnicos do passado, há entre elas uma clara derivação. Mais ainda: através delas, passa o fio de intermináveis derivações que provém de um passado remoto, dos primeiros escritos sobre o conhecimento sagrado da matéria; ou do que poderíamos considerar a mais antiga química secreta, praticada por artesãos vidreiros, metalurgistas e tintureiros. ${ }^{16}$

Sem dúvida, os pesquisadores modernos tiveram bons motivos para afirmar que os textos iatromatemáticos, talismânicos e principalmente os alquímicos pertencem à mesma linhagem dos textos herméticos. Mas a total confusão entre esses últimos e os primeiros foi causada pela falta de um olhar atento ao contexto que define a articulação enciclopédica pretendida pela hermética.

De fato, os "livros de segredo", que por milênios foram guardados por corporações e castas fechadas, desembocaram na hermética, e através,

${ }^{14}$ H. Stapleton et alii, Memoris of the Asiatic Society of Bengal, Vol. I, n. ${ }^{\circ} 4$, Calcutta, Baptist Mission Press, 1905; os estudiosos referem-se ao simbolismo nebuloso e desnecessário que, a partir do século X, começa a imperar nos textos "alquímicos", em contraste com aqueles do século anterior; naturalmente, esses estudiosos consideram que estão comparando obras do mesmo estatuto, sem perceber que os textos do século IX pertenciam à hermética; por exemplo, M. Manzalaoui, "The Pseudo-Aristotelian Kitab Sirr al-Asrar", surpreende-se claramente ao constatar que os tratados alquímicos homônimos da obra hermética por ele estudada não são equivalentes à esta; a perplexidade desse notável arabista deriva da suposição de que hermética e alquimia são termos sinônimos, já que a última se constitui na "parte" mais importante e às vezes a mais extensa da hermética; esta suposição repete-se nas obras dos mais variados estudiosos; W. Eamon, op. cit, p. 34-5, por exemplo, constata a visível fragmentação, e a conseqüente perda do sentido original, sofridas por textos herméticos em desmembramentos futuros, embora nada conclua de relevante sobre essa preciosa constatação.

${ }^{15}$ B. Copenhaver, op. cit, p. XXXII et seq., fala longamente sobre o debate moderno; vide também meu artigo "Questões sobre a hermética: uma reflexão histórica sobre algumas raízes pouco conhecidas da ciência moderna”, Vozes/Cultura, Vol. 88, n. ${ }^{\circ} 4,1994$, p. 13-20.

${ }^{16}$ Existe uma vasta literatura a esse respeito; vide, por exemplo, M. Eliade, Cosmologia y Alquimia Babilónicas, trad. castelhana, Barcelona/B. Aires/México, Paides, 1993, em especial capts. II e IV. 
desta nas obras de alquimia, magia operativa e, mais adiante, polimatias e "miscelâneas curiosas" do Renascimento e início da modernidade. Os Ikhwân indicaram esses documentos arquétipos como fonte da hermética. Igualmente, indicaram a elaborada e singular composição dessas fontes nos textos de linhagem exclusivamente hermética.

Assim, a pesquisa revelaria que a composição enciclopédica da hermética se dá em torno da preservação simbólica do conhecimento secreto em sua íntegra. O gradativo desmembramento dessa fórmula textual, ao que parece, teria sérias conseqüências na maneira de ver e operar sobre a matéria.

\section{SOBRE A PESQUISA ESPECÍFICA NA OBRA DE JOHN WILKINS E A ARTICULAÇÃO DAS FONTES POR ELE USADAS}

Um estudo prévio revelou a existência de cinco grandes temas no Mathematical Magick de John Wilkins (cosmologia, língua, química, mecânica e magnetismo), indicando vestígios certos da antiga literatura de segredo nesta obra ${ }^{17}$.

Todavia a articulação entre esses temas, embora indicando a velha fórmula dos livros de segredo, ainda parecia requerer uma longa e complexa pesquisa. Enquanto em temas como a língua universal e a mecânica Wilkins estava claramente no limiar da modernidade, aqueles sobre o magnetismo e a química respiram uma visão de mundo e, sobretudo, de matéria absolutamente antiga. Isto poderia significar apenas o estágio em que cada um desses campos se encontrava em sua época, não fosse porque autores respeitados como Bacon e Galileu já haviam descartados a série de influências sutis que Wilkins imprime à matéria.

Principalmente, em seu tópico sobre a química, uma visão antiquíssima e quasi alquímica sobre a matéria se faz presente. A contraposição frontal entre o primeiro livro do Mathematical Magick e esse tópico, contido no segundo livro dessa obra, foi um dos pontos exaustivamente estudados por

${ }^{17}$ Vide meu artigo "Na 'Older' View about Matter in J. Wilkins' 'Modern' Mathematical Magick" in Reading the book of Nature: the other side of the Scientific Revolution; A. Debus \& M. Walton (orgs.) Kirksville, Sixteenth Century Publ., 1998. p. 133-146. 
esta pesquisadora no último ano e meio, gerando seminários, apresentações e publicações no país e no exterior, conforme pode ser visto no currículo.

Conforme já havia sido visto em estudos anteriores, o Mathematical Magick, teria duas faces distintas, aparentemente, exigindo também duas leituras diferenciadas.

A primeira dessas faces, representada pelo livro I do compêndio, significativamente denominado "Archimedes: or Mechanical Powers" 18 . Ali, as chamadas máquinas simples aparecem como elementos matematizáveis a formar a base da nova teoria mecânica. Descartando, portanto, os argumentos teleológicos desenvolvidos no tratado aristotélico OnMechanics, mas preservando deste o suficiente para criar um interplay com trabalhos clássicos de geômetras como Arquimedes. Resultado: "Archimedes: or Mechanical Powers" será um bom exemplo da chamada matemática mista,indicando um estilo "moderno" de fazer ciência. Mais ainda, porque ao usar o modelo da máquina para interpretar todo e qualquer fenômeno de movimento, Wilkins estaria inserindo um claro viés mecanicista nesta parte de sua obra.

Entretanto, no segundo livro que compõe a obra não se dá a esperada continuidade dos procedimentos existentes no primeiro. Em "Daedalus: or Mechanical Motions" ${ }^{19}$ misturam-se lendas, fatos pitorescos e uma série de explicações sul generis a toda uma parafemália de equipamentos e efeitos maravilhosos, mas pouco factíveis. Lembrando antigas poligrafias, como a de Plínio, ou mais ainda as "miscelâneas curiosas" renascentistas, o segundo livro do Mathematical Magick tem paralelo, no Seiscentos, em obras nada "mecanicistas" e pouco "modernas", como a de Athanasius Kircher.

Em "Daedalus" parece estar representada uma outra face do pensamento de Wilkins. Uma face ainda voltada para um arcabouço antigo, embora escrita no linguajar moderno, onde se encontram os capítulos sobre "lâmpadas eternas" contendo a visão química mantida por Wilkins e, portanto, suas idéias sobre a matéria.

\footnotetext{
${ }^{18}$ A edição aqui usada encontra-se em The Mathematical and Philosophical Works of J. Wilkins. Londres: J. Nicholson, 1708, cf. p. 1-84

${ }^{19}$ Ibid. p. 85-167
} 
Como seria de se esperar, Wilkins começa esse tópico com mais dúvidas do que certezas sobre as elevadas pretensões de alguns alquimistas. Mas percebe-se em outros exemplos oferecidos nesse capítulo que Wilkins não pretende desacreditar as possibilidades do trabalho alquímico, apenas fazer críticas a algumas formas de realizá-lo ou aos argumentos usados por certos alquimistas. De tal sorte que, na seqüência, Wilkins procura dar exemplos autorizados que indicariam as possibilidades do moto perpetuo através da via química. E, por acreditar que "violência e eternidade não são companheiras" ${ }^{20}$, a maioria dos exemplos referem-se as chamadas "lâmpadas eternas" ou "perpétuas" que teriam ardido suave e constantemente.

Segundo foi indicado anteriormente, a fim de melhor entender essa argumentaçao de Wilkins, realizou-se um escrutínio sobre a montagem de seu texto. Existem, apenas nessa parte, quase trinta fontes ordenadas à maneira singular das antigas doxografias, dando ao texto uma conformação nada moderna. A análise dessas fontes dá indicações de que elas passam ser classificadas em duas linhagens gerais. A primeira destas conteria as fontes onde Wilkins busca relatos ou idéias que possam autorizar a sua argumentação. A voz de Aristóteles estaria incluída nessa linhagem e do mesmo modo a de uma autoridade mais recente como Francis Bacon. Mas também estariam neste caso, polígrafos reconhecidos de épocas diversas, variando desde Plínio até alguém do século e contexto do próprio Wilkins, como Willian Camden. Por últimos, mas talvez os mais importantes nesta linhagem de apoio, estariam relatos teológicos cristãos. Preferencialmente de cunho reformista, essas fontes comportam tanto a versão ao De civitat Dei agostiniano que Luis Vives fez por encomenda de Erasmo, quanto a obra do teólogo protestante italiano Girolamo Zanchi, "o judicioso", conforme o chama Wilkins.

Já, na segunda linhagem de fontes a esse tópico do Mathematical Magick, pode ser incluída uma grande variedade de obras que vão dos "livros de segredo"- pouco recomendáveis num texto supostamente moderno como o de Wilkins - aos tratados sobre curiosidades da natureza e maravilhas da técnica.

${ }^{20}$ Ibid., p. 131 
Ombreiam-se, portanto, nessa segunda linhagem, trabalhos populares como o pitoresco De secretis de Joannes Wecker, ou o Magiae naturalis de della Porta, nas mesmas condições de tratamento dadas ao Confession da fraternidade Rosa Cruz ou a um texto hermético ali referido. Genérica quanto possa parecer essa última classificação, a ela pertenceriam fontes menos autorizadas - algumas vezes sem sequiência explícita no texto - que Wilkins usa para ampliar seus argumentos, geralmente iniciados ou ancorados no terreno firme de alguma autoridade.

Assim, quando se refere às "lâmpadas perpétuas" como objeto principal de suas investigações, nesse tópico, Wilkins pondera que fará isso pois:

"apesar de não ser tão próprio ao objetivo principal dessa discussão que diz respeito à Geometria Mecânica; contudo, a sutileza e a curiosidade do assunto pode exigir [...] a impertinência".

e como um modo de justificar plenamente essa impertinência, anuncia a seguir:

"há vários autores tratando deste assunto [...] de quem irei emprestar muitas das relações e opiniões que irão naturalmente dirigir a presente discussão. ${ }^{21}$

Portanto, testemunhos autorizados sobre "lâmpadas perpétuas" encontradas em antigos mausoléus ou câmaras secretas, precedem ou mesmo envolvem aqueles testemunhos não tão autorizados. Não sem antes fazer menção a uma lâmpada "que continuou ardendo por 1050 anos" citada por Santo Agostinho, Wilkins dará o exemplo da lâmpada "relacionada àquela vista no sepulcro de Francis Rosicrosse" 22 . Do mesmo modo, Wilkins cita um exemplo dado por della Porta, fazendo com que cuidadosamente caiba

${ }^{21}$ Ibid., p. 134

22 Ibid., p, 134-7 Ibid., p. 136; S. Agostinho, The City of God (trad. e coment.) L. Vives, 2, ed. Londres: G. Eld \& Flesher, 1620. cap. 6, p. 789-91; na verdade essa ref. Está na Fama, cf. Fame and Confession of the Fraternity of R.C. (ed.) Facsimilar da de 1652, Margate, Soc. Rosi. In: Anglia, 1923. 
entre um relato de um obscuro mas seguro humanista do século XV e outro de Fortunius Licetus, o único autor válido, segundo Wilkins, "que escreveu objetiva e extensamente a este respeito" ${ }^{23}$.

Sabendo estar lidando com um assunto delicado, Wilkins, chega a citar a ocorrência de milagres divinos que teriam renovado o fogo ritual dos judeus, apoiado em referências a livros do Antigo Testamento. Mas Wilkins, como excelente representante da corrente dos chamados "teólogos naturais" ingleses, usará argumentos menos dogmáticos e bastante afastados daqueles oferecidos pela teologia tradicional para explicar as lâmpadas perpétuas. Em obras teológicas tradicionais, como a de Santo Agostinho ou Zanchi, essas lâmpadas - ao contrário do exemplo acima - eram consideradas quase sempre um feito demoníaco dos povos pagãos ${ }^{24}$. Entretanto, Wilkins tenta, na medida do possível, evitar essa perspectiva mais estrita em seu texto, onde irá abrindo espaço para obras sobre maravilhas da arte e da natureza que lhe darão muitos dos elementos de sua argumentação. Esse tipo de obra servirá, por outro lado, para complementar as referências a obras clássicas usadas por Wilkins, emprestando a seu texto um tom mais atualizado e popular. Existiria, portanto, toda uma coerência e um propósito na ordenação e uso das fontes por Wilkins.

Essa estrutura, na verdade, guardaria vários pontos em comum com alguns documentos antigos, como a enciclopédia de Isidoro de Sevilha ${ }^{25}$ onde, por trás do aparente emaranhado de referências e relatos, existe um rigoroso tratamento de ordenação e uma criteriosa argumentação clássica. Wilkins, aliás, anuncia explicitamente essa fórmula quando diz que: "para melhor compreender isso [ou seja, os relatos sobre as lâmpadas perpétuas], devem ser explicados estes dois particulares: $1^{\circ}$ ) quod sit $2^{\circ}$ ) quomodo sit'26. Portanto, à moda tradicional, primeiro uma longa relação, cujo exemplo já foi visto brevemente aqui, categorizando quem deu, onde e quando foi dada fé sobre a existência de tais lâmpadas. Depois, uma

${ }^{23}$ Wilkins, op. cit., p. 135-6; F. Licetus De lucernis antiquorum reconditis, Veneza: E. Deuch, 1621.

249 S. Agostino, op, cit., p. 789, G. Zanchi. Operum Theologicorum, v. I, liv. 4, Roma: S. Gamonetus, 1605. p. 194

${ }^{25}$ Isidorus Sevillanus. Etymologiae. Augsburg: G. Zouner, 1472.

${ }^{26}$ Wilkins, op.cit.p. 134, 
segunda seqüência, onde as conjecturas sobre a natureza dessas lâmpadas e seu modus faciendi seriam discutidos. Essa seqüência constitui um lugar privilegiado para se apreciar mais especificamente a visão de Wilkins sobre a química e foi estudada por nós detidamente.

Wilkins começa essa última parte sobre as lâmpadas perpétuas oferecendo dois tipos de conjecturas, a dos que pensam não serem elas “... fogo nem chama, mas tão só alguns destes corpos geralmente brilhando em locais escuros". Enquanto, um segundo tipo de autores conjetura que exista fogo nessas lâmpadas, "mas supõe serem elas acessas mediante a admissão de ar novo, quando estes sepulcros são abertos" ${ }^{27}$. Essa segunda será, sem dúvida, a favorita de Wilkins, enquanto a primeira pode-se notar que ali comparece para cumprir o velho preceito clássico de se enfocar os vários lados de um problema. De tal sorte que, nosso autor, indica como única fonte para se verificar quais pensadores acreditaram que tais lâmpadas fossem corpos luminescentes, o livro De lucernis de Fortunio Licetus. Entretanto, aproveita para montar brevemente uma séries de conjecturas sobre esses corpos luminescentes que devia julgar, em si, matéria de grande interesse. Começa citando o De anima onde Aristóteles, fala de corpos com luz própria como as escamas de certos peixes, pedras e olhos de certas criaturas. E, na seqüência, refere-se ao De subtilitate de Girolamo Cardano onde é descrito o pássaro Cocoyum da Nova Espanha de corpo brilhante e olhos mais brilhantes ainda. Detém-se, ainda que de forma breve, no exemplo do carbúnculo, a lendária pedra que "brilharia no escuro". E cita a referência clássica a essa lenda em Claudius Aelianus, Historia animalium, escrito no século III da era comum. Embora, em seguida, mencione a opinião recente de Anselmo de Boot que em seu Gemmarum et lapidum historia desacredita a existência de tão fantástica pedra ${ }^{28}$. Enfim, Wilkins faz esse breve percurso para chegar a conclusão de que:

27 Ibid., p. 137-8

${ }^{28}$ Aristóteles, On Ihe Soul, in The basic books of Aristotle, 27 reimp. (ed.) R. Mckeon, N. York: Random house, 1941. liv.II, cap. 7; G. Cardano. De subtilitate, G. Rouillium, 1559. liv. 9; Wilkins cita Aelianos usando Boetius de Boot, cf. Gemmarum et lapidarum historia (reed.); Leiden:J. Marre, 1647, cap.8, p. 140-1. 
“.., nenhum destes corpos brilhantes tem sido observado em nenhum dos antigos sepulcros, e por tanto, isto é uma conjectura imaginária"29

Wilkins irá preferir, pois, a conjectura de que as lâmpadas são uma forma de chama eterna e, aliás, indica na glosa subsequente, que ali está de fato o quomodo dessas lâmpadas. Ou seja , busca exclusivamente as formas de manter essas lâmpadas brilhando, senão eternamente, pelo menos através das eras - bem ao gosto de qualquer alquimista à moda antiga. Os dois aspectos que, segundo ele, devem ser considerados para a continuidade dessa chama seriam a mecha que a mantém e o óleo que a nutre.

Quanto ao primeiro desses aspectos, Wilkins entende que essa mecha poderia ser feita de matérias que resistiriam ao fogo sem se consumir como a chamada lã de salamandra, um produto mineral citado por Bacon e outros autores. Ou ainda o linum vivum dos antigos, sobre o qual nosso autor, procura dar várias referências pois sua origem, certamente mineral, não estava bem identificada na época. O próprio Wilkins considera que seja uma denominação geral de diversos materiais que també poderiam ser chamados de asbestos. Entretanto, levanta o inconveniente de que esse tipo de mechas “.., contrai tanto material fuliginoso das partes terrosas do óleo [...], que em poucos dias [...] extingue a chama” ${ }^{30}$. Como também não consegue lembrar de nenhum relato que mencione o uso de mechas nessas lâmpadas, abandona tal investigação e se dedica exclusivamente à causa que produziria a chama perpétua em si.

Suas atenções voltam-se, assim, para o caso de lâmpadas colocadas num vaso esvaziado de todo conteúdo e extremamente bem vedado que se puderem brilhar ali por um momento, brilharão para sempre, pois do contrário: “... haveria vácuo [algo] que a natureza é incapaz [de realizar]..."31

${ }^{29}$ Wilkins, op. cit, 138-9

${ }^{30}$ Ibid., p. 141

${ }^{31} \quad$ Ibid., p, 143 
Wilkins assume, portanto, o velho discurso do horroris vacuu e chega a dar um exemplo de lâmpada desse tipo que teria sido encontrada. Já na seqüência, nosso autor, fará um longo, e último arrazoado nesse tópico, sobre extratos que "alimentam a chama com pouco ou nenhum desgaste de sua substância” e oferece, logo de saída, o exemplo de ouro que pode ser “.., dissolvido num humor oleoso; ou, se a umidade radical deste metal fosse separada, pode ser que arda, talvez para sempre ou, pelo menos durante muitas eras... "32.

E, nesse mesmo espírito, quasi alquímico comenta na seqüência, nem mais nem menos que um tratado de hermética. Apesar de não dar a referência específica, percebe-se pelo todo de seu comentário que se trata de um dos pseudo-epigráficos medievais, onde se prova “...que Urim e Thummim devem ser criados pela arte." ${ }^{33}$, um feito que 0 autor compara à luz artificial que por ordem divina Noé teria levado em sua arca, conforme o Genesis. Wilkins conclui usando essa comparação para dizer que talvez a preparação química da luz seja a resposta às lâmpadas subterrâneas.

No único comentário que se segue, Wilkins aproveita para fazer menção, através de Licetus, ao De ignes, do velho e bom Theophrastus, onde se diz que o fogo ao ser um dos principais elementos não necessitaria para substituir de nenhum tipo de alimento, e qualquer humor ali acrescido serviria apenas para impedir a chama “... de subir”. Haveria, por sinal, três tipos de combinação "entre o fogo e o humor ou matéria deste.” Duas delas onde a proporção de um excederia a do outro, extinguindo a chama, e uma terceira, em que " as proporções seriam equivalentes quanto as suas virtudes [como entre a umidade radical e calor natural nos seres vivos] então nenhuma das partes pode superar ou destruir a outra, o que garante a continuidade da chama" ${ }^{34}$.

${ }^{32}$ Ibid., p.144, posição contraria já em Bacon, cf. Histoiria densi et rari, in The works of F. Bacon, (org.) Spedding \& Ellis \& Heath, v. 10, Boston: Brown \& Taggard, 1861, p. 262

${ }_{33}$ Wilkins, op. cit., p. 145; Samuel 28:6; Exodos 28:15-30.; sobre esses tratados herméticos cf. M. Plessner ,"Hermes Trismegistus and Arab Science", Studia Islamica, v.2, p.53-4,1954

3419 Wilkins, op. cit., p. 145; Teofrasto, De igne, ed. Bilingue, V. Coutant, Assen: Royal vangorcum, 1971 , principalmente entrada 4. 
A preocupação em explicar a natureza do fogo ocorre especialmente nesse ponto do texto de Wilkins porque, na seqüência, ele irá supor que os antigos esconderam essas lâmpadas em lugares fechados devido a que: “...a admissão do novo ar na lâmpada causa uma desigualdade tão grande entre a chama e o óleo, que esta se extingue. “35

Portanto, a grande dificuldade das lâmpadas perpétuas estaria em saber a exata proporção "entre um humor oleoso e uma qualidade ativa como o calor do fogo...", além da dificuldade de saber preservar essa perfeita proporção depois. Oferece, assim, a título de conclusão as sugestões de Licetus de que sejam extraídos para esse fim : “...um óleo inflamável obtido da pedra Asbestus, do Amiantus, ou do ouro metálico, o qual [...] deverá ser proporcional ao calor do fogo..." ${ }^{36}$ e arremata dizendo que está dentro do poder da química realizar esses estranhos efeitos, já que entre seus experimentos comuns tem, por exemplo, o do chamado aurum fulminans através do qual, com um pouquinho, se consegue realizar uma explosão. Não seria, pois, impossível através dessa mesma arte conseguir o precioso óleo. Depois dessa discussão alquímica encerra dizendo que esses conhecimentos pereceram em meio a outras ruínas do tempo e novamente culpa os alquimistas de sua época, ao serem os mais versados nessa busca de tê-la "recoberto de negras conjecturas." ${ }^{37}$ Wilkins, aliás, já havia manifestado uma certa tendência a igualar o moto perpétuo à pedra filosofal dos alquimistas, antes mesmo de começar a discussão específica sobre química ${ }^{38}$.

A partir deste último período de pesquisa, se obteve, portanto, um modelo bem definido da estrutura textual e argumentativa usada por Wilkins em sua obra. Mas também esta análise indicou que o pensador inglês mantinha concepções qualitativas sobre a matéria e, por conseguinte, incoerentes com a de outros mecanicistas. Incluídos aí aqueles como

${ }^{35}$ Wilkins, op. cit., p. 145-6

${ }^{36}$ Ibid., p.146; cf, também G. Tierie. Cornelius Drebble. (trad, inglesa) Amsterdam: H-J Paris, 1932. p 74-5

37 Wilkins, op. cit., p. 146.

${ }_{38}$ Ibid., p. 130-1 
Boyle que, a partir de uma visão atomística da matéria, acreditavam na transmutação.

No caso de Wilkins, todavia, essa concepção - sempre básica na arquitetura de qualquer pensamento - seria coerente com a fórmula de enciclopédia antiga usada em sua obra. Algo que, de todo modo, também será um indício de sua maneira de pensar. A análise detalhada desse complexo cenário, merece ainda uma investigação mais detalhada. Mas a pesquisa até aqui já indica, de várias maneiras, a permanência (mesmo que vestigial) de antigas fontes na Ciência do seiscentos em textos considerados até há pouco radicalmente modernos. 
